The American Mathematical Monthly, 87 (1980), pp. 527-542.

\title{
ON THE DEVELOPMENT OF OPTIMIZATION THEORY
}

\author{
András Prékopa
}

\section{Introduction}

Farkas's famous paper of 1901 [23] became a principal reference for linear inequalities after the publication of the paper of KunN and Tucker, "Nonlinear Programming", in 1951 [53]. In that paper Farkas's fundamental theorem on linear inequalities was used to derive necessary conditions for optimality for the nonlinear programming problem. The results obtained led to a rapid development of nonlinear optimization theory. The work of John [50] containing similar but weaker results for optimality, published in 1948, has been generally known, but it was not until a few years ago that Karush's work [51] of 1939 became widely known, although essentially the same result was obtained by Kuhn and Tucker [53] in 1951.

In this paper we call attention to some important work done in the last century and before. We show that fundamental ideas about the necessary optimality conditions for nonlinear optimization subject to inequality constraints can be found in papers by Fourier, Cournot, and Farkas, as well as by Gauss, Ostrogradsky, and Hamel.

To start to describe the early development of optimization theory it is very helpful to look at the first two sentences in Farkas's paper [23]:

The natural and systematic treatment of analytical mechanics has to have as its background the inequality principle of virtual displacements first formulated by Fourier

András Prékopa received his Ph.D. in 1956 at the University of Budapest under the leadership of A. Rényi. He was Assistant Professor and later Associate Professor of Probability Theory at the same university. Since 1968 he has held a professorship of mathematics at the Technical University of Budapest. He is also head of the Applied Mathematics Department at the Computer and Automation Institute of the Hungarian Academy of Sciences. He is a corresponding member of the Hungarian Academy of Sciences, the National Academy of Engineering of Mexico, member of the I.S.I., and Fellow of the Econometric Society. His main interests are in Probability, Statistics, and Operations Research, including application in engineering design (water resources, electrical engineering), economics, and natural sciences. This paper was prepared while the author was visiting the Mathematics Research Center of the University of Wisconsin-Madison. Readers who are not familiar with the subject whose history is discussed in this article should consult Pourciau's article in this Monthly, 87 (1980) 433-451. - Editors 
and later by Gauss. The possibility of such a treatment requires, however, some knowledge of homogeneous linear inequalities that may be said to have been entirely missing up to now.

We see that Farkas had a definite reason for developing the theory of linear inequalities. He was Professor of Theoretical Physics at the University of Kolozsvár. We can certainly assume that he himself had already applied his inequality theorem to the problem of mechanical equilibrium. In fact, he reported first "on the applications of the mechanical principle of Fourier" at the session of the Hungarian Academy held on December 17, 1894 . This was published later in Hungarian [13] and in German [14]. We shall analyze this paper in more detail in further sections. We present here, however, a brief summary of the problem and the principal result.

The method of Lagrange for finding extrema of functions subject to equality constraints was published in 1788 in his famous book Mécanique Analytique as a tool for finding the stable equilibrium state of a mechanical system. In the case when a potential exists, the Lagrangian problem can be formulated in the following manner:

$$
\begin{array}{ll}
\operatorname{minimize} & g(x) \\
\text { subject to } & g_{i}(x)=0, \quad i=1, \ldots, m,
\end{array}
$$

where the objective function is the potential. The case of inequality constraints was first investigated in 1798 by Fourier [34]. If a potential exists, then Fourier's problem is

$$
\begin{array}{ll}
\text { minimize } & g(x) \\
\text { subject to } & g_{i}(x) \geq 0, \quad i=1, \ldots, m,
\end{array}
$$

Assuming that the constraining and the objective functions are differentiable and some regularity conditions hold, the Lagrangian necessary condition for the equilibrium states that at the minimizing point $x^{*}$ the gradient $\nabla g\left(x^{*}\right)$ can be expressed as a suitable linear combination of the gradients $\nabla g_{i}\left(x^{*}\right), i=1, \ldots, m$.

For Fourier's problem the necessary condition for equilibrium was proved by Farkas in 1894 [13] and 1898 [17]. This condition, formulated without proof for special cases by Cournot in 1827 [4] and for the general case by Ostrogradsky in 1834 [67], is that at the minimizing point $x^{*}$ the gradient $\nabla g\left(x^{*}\right)$ can be expressed as a linear combination with nonnegative coefficients of those gradients $\nabla g_{i}\left(x^{*}\right)$ whose corresponding constraints hold with equality at $x^{*}$.

Figure 1 illustrates the situation. The constraints restricting a mass point are five half-spaces. Choosing the coordinate system so that the $x_{1}, x_{2}$ plane coincides with the plane of the ground, the potential corresponding to the gravitational force is given by the well-known formula $m g x_{3}$, provided $x_{3}$ is small as compared to the radius of the earth. At the equilibrium point $x^{*}$, four constraints hold with equality and the cone generated by their negative gradients contains the vector of the gravitational force. 


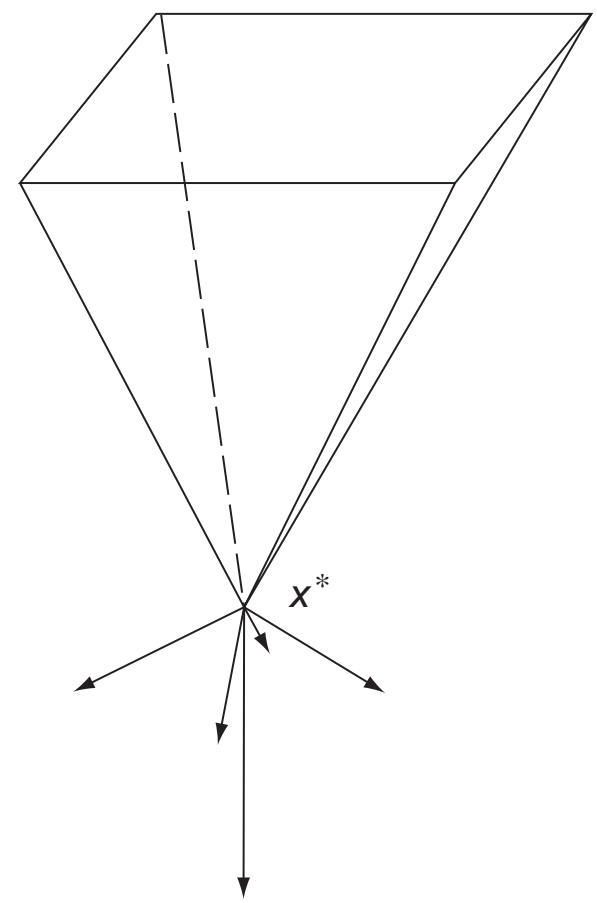

Figure 1: The mass point is in stable equilibrium at $x^{*}$; the vector of the gravitational force is in the cone generated by the negatives of the gradients of the constraining functions at $x^{*}$.

Now we need to say a few words about those mechanical principles which played an important role in the development of optimization theory.

\section{On the Principles of Mechanical Equilibrium}

The principle of virtual work was enunciated by Johann Bernoulli in 1717 . It appeared first in a book by Varignon in the same year. Let us quote Lagrange [55, I, pp. 21, 22]:

The principle of virtual velocity can be given the following general form.

If a system of any number of bodies or points on each of which any forces act is in equilibrium, and one gives the system some small displacement on the basis of which each point moves an infinitesimal distance that will express its virtual velocity, the sum of the forces, each multiplied by the distance moved by the corresponding point in the direction of the force, will always be equal to zero, if infinitesimal displacements in the direction of the forces are taken as positive, and those in the opposite direction, negative. 
John Bernoulli is the first as far as I know, who observed this great general form of the principle of virtual velocity and its usefulness for the solution of the problems of Statics. One can see this in one of his Letters to Varignon, dated 1717, which Varignon placed at the beginning of the ninth Section of his New Mechanics, a Section which is entirely devoted to showing by means of different applications the truth and the use of the principle in question.

This principle was considered by Lagrange as an axiom of Mechanics. On page 27 of the same work we read:

In this law lies what is generally called the principle of virtual velocity, which has been recognized for a long time as the fundamental principle of equilibrium, as we have described it in the preceding Section, and we can consequently consider it as a kind of an axiom of Mechanics.

For the case of a conservative system of forces, i.e., when the forces are given as negative partial derivatives of a scalar function, the principle, first enunciated by Courtivron, applies. Concerning this, Lagrange writes the following [55, I., p. 70]:

... which yields a further principle of Statics, namely that out of all configurations that are successively assumed by the system, the one in which it has the greatest or the smallest kinetic energy is also that in which it would have to be placed in order for it to remain in equilibrium. [See Courtivron, Mémoires de l'Académie des Sciences of 1748 and 1749.]

Lagrange gave sufficient conditions that the potential takes its minimum. As Bertrand remarked, his proof was incomplete and Dirichlet later gave a correct proof [10], [11].

The mechanical principle of Fourier was first published in 1798 in his paper "Mémoires sur la Statique". This concerns the case of inequality constraints. Farkas remarked [13, p. 458] that the declaration of the inequality principle is not the main contribution of the paper. It has the subtitle: "Contenant la démonstration du principe des vitesses virtuelles". This very general "proof", however, has not been accepted (see, e.g., [75]); thus the main merit of the paper is still, contrary ot Farkas's remark, the statement of the inequality principle. We quote from page 488 of Fourier's paper [34]:

As it frequently happens that the points of the system are only constrained by fixed obstacles, without being attached to them, it is evident that there are possible displacements that do not satisfy the equations of constraint; one also sees that for these displacements the moment of the resulting forces is necessarily positive, since the direction of these forces has to be orthogonal to the resisting surfaces. Thus the 
sum of the moments of the applied forces is positive for all displacements of this kind; but it is impossible to displace a solid body that is in equilibrium so that the total moment of the applied forces will be negative. Finally, if one considers the resistances as forces, which provide us, as we know, with the means of estimating these resistances, the body can be considered free and the sum of the moments is zero for all possible displacements.

The moment of the forces $P, Q, R, \ldots$ acting on a mechanical system is defined as the sum of scalar products

$$
P \delta p+Q \delta q+R \delta r+\cdots,
$$

where $\delta p, \delta q, \delta r, \ldots$ are variations of the displacements. The Bernoulli principle declares (2.1) to be equal to zero, while the Fourier principle declares (2.1) to be less than or equal to zero in case of equilibrium. Fourier was using the "fluxion", as it turns out from other parts of his paper, instead of the displacement, these two being negatives of each other. This explains why Fourier required (2.1) to be nonnegative.

If a potential $V$ exists, i.e., if we have

$$
P=-\frac{\partial V}{\partial p}, \quad Q=-\frac{\partial V}{\partial q}, \quad R=-\frac{\partial V}{\partial r}, \ldots,
$$

where the derivatives on the right denote vectors, then the requirement that (2.1) is less than or equal to zero takes the form:

$$
\frac{\partial V}{\partial p} \delta p+\frac{\partial V}{\partial q} \delta q+\frac{\partial V}{\partial r} \delta r+\cdots \geq 0
$$

On the left side we have a total differential. A correct mathematical proof - according to our present standards - cannot be found in Fourier's work. We know, in particular, that (2.2) cannot be derived as a necessary condition that $V$ takes its minimum, without some constraint qualification. Fourier remarked that in the case where his principle reduces to (2.2), we can find the equilibrium state by minimizing (!) the function $V$.

In 1829 Gauss [38] again enunciated the inequality principle without mentioning Fourier. He added a footnote explaining his ideas in more detail.

According to the principle of virtual velocities this equilibrium requires that the sum of products of all three factors, namely, each of the masses $m, m^{\prime}, m^{\prime \prime}$, etc., the line segments $c b, c^{\prime} b^{\prime}, c^{\prime \prime} b^{\prime \prime}$, etc., and the projections of the possible motions of the corresponding points in accordance with the constraints, should be equal to zero, as it is ordinarily stated, or more exactly that the above sum should never be positive.

Footnote: 
The ordinary expression tacitly assumes such constraints as allow the opposite for every possible motion, as, e.g., that a point must remain on a certain surface, that the distance between two points should be fixed, and so on. But this is an unnecessary restriction and does not always correspond to Nature. The surface of an impenetrable body does not compel a material point to remain on it but merely prevents it from going to the other side; an inextensible but flexible cord connecting two points prevents only the increase but not the decrease of the distance, etc. Why should we not prefer to express the law of virtual velocities from the very beginning so that it covers all cases?

In 1834 Ostrogradsky also enunciated the inequality principle at a session of the Académie Impériale des Sciences de Saint-Pétersbourg. Voss remarks [75, p. 74] that therefore in Russia it is also called Ostrogradsky's principle. It is interesting to read what Ostrogradsky [68] wrote about the inequality principle:

It is very surprising to see that in the new edition of the Mécanique Analytique, published at a time when the full extent of the principle of virtual velocity was already known, Lagrange not only did not make any use of the observation that in the equilibrium of forces the total moment may acquire a negative value, but in a way he ruled it out when it turned up naturally in the proof he gave for the principle of virtual velocity; meanwhile, failing to take account of it, this great mathematician incompletely enumerated the possible displacements in most of the questions of the first part of the Mécanique Analytique and it is easy to recognize that the displacements he neglected to consider are not forbidden by any condition, so that even when all the equations that he established for the equilibrium are satisfied, equilibrium may not occur.

In this memoir we propose to expound the analysis of the use of the principle of virtual velocity considered in its utmost generality and to complete the solution of various questions handled in the first part of the Mécanique Analytique.

Lagrange's method of multipliers was published in the first volume of Mécanique Analytique, pp. 77-79, as a tool for finding the equilibrium of a mechanical system using Bernoulli's principle. The validity of the method was proved by Lagrange entirely on an algebraic basis. (This ingenious method was unable to attract mathematics students and teachers for a long time. The method of presentation used nowadays by many instructors is to prove the necessary condition first in the case of inequality constraints, give a geometric meaning to this, and then refer to the case of equality constraints. This can make the students more enthusiastic about this theory.) We shall see in Sections 4-7 what happened to Fourier's principle. Now we devote a few pages to Farkas's theorem. 


\section{The Theorem of Farkas on Linear Inequalities}

Gyula Farkas (1847-1930), a former member of the Hungarian Academy of Sciences, contributed primarily to theoretical physics. In this respect his results in Mechanics and Thermodynamics are the best known. For further information concerning his life and work see [32], [33], [65], [66], [73].

Farkas's 1901 paper [23] is generally cited for the fundamental theorem on homogeneous linear inequalities. In what follows we shall write vectors in column form, and the transpose will be denoted by a prime.

Let $g_{1}, \ldots g_{M}, g$ denote $m$-component vectors and form the following homogeneous linear inequalities:

$$
\begin{aligned}
& g_{i}^{\prime} x \geq 0, \quad i=1, \ldots, M, \\
& g^{\prime} x \geq 0
\end{aligned}
$$

If (3.2) holds for every $x$ for which all inequalities in (3.1) hold, then we say that the inequality (3.2) is a consequence of the system of inequalities (3.1). Farkas's theorem is the following.

TheOrem 3.1. The inequality (3.2) is a consequence of the inequalities (3.1) if and only if there exists nonnegative numbers $\lambda_{1}, \ldots, \lambda_{M}$ such that

$$
g=\lambda_{1} g_{1}+\cdots+\lambda_{M} g_{M}
$$

Farkas published this theorem first in 1894 and 1895 [13], [14]. However, the proof contains a gap. The second proof that he gave in 1896 [15] in Hungarian is also incomplete. Essentially the same paper appeared in German in 1899 [16]. The first complete proof was published in Hungarian in 1898 [17] and in German in 1899 [18]. This proof is included in his best-known paper [23]. It is instructive to see what kind of error he made in the first proof. We shall quote form [14].

First he shows that we may suppose that there are as many linearly independent inequalities in the system, of which one consequence is considered, as the number of variables. Then he represents the coefficient vector of the consequence inequality as a linear combination of the other coefficient vectors. Now if, for the sake of simplicity, the first $n$ inequalities are linearly independent, then we can express the multipliers belonging to these in terms of the others in the following manner

$$
\begin{aligned}
\lambda_{1}= & I_{0}+I_{1} \lambda_{n+1}+I_{2} \lambda_{n+2}+\cdots \\
\lambda_{2}= & K_{0}+K_{1} \lambda_{n+1}+K_{2} \lambda_{n+2}+\cdots \\
& \vdots \\
\lambda_{n}= & \cdots .
\end{aligned}
$$


What Farkas then writes can be summarized as follows: a necessary condition that it is impossible for all $\lambda$-values simultaneously to assume nonnegative values is that, in (3.4), or in one of its equivalent forms that can be obtained using subsequent eliminations, at least one right-hand side has the two properties that its first terms is negative and the coefficients of the remaining terms are either negative or zero.

Farkas seems to have had in mind a procedure similar to what is used in the dual (simplex) method. We know, however, that cycling is possible there [2]. We can correct the proof by applying the lexicographic dual method [57]; a short presentation is given in [70]. Let us summarize the whole corrected proof briefly.

Proof of Farkas's theorem. First we remark that if we apply a linear transformation $y=B x$, where $B$ is a nonsingular square matrix, to the inequalities (3.1), (3.2), then the new (3.2) inequality will be consequence of the new (3.1) system. Furthermore, proving Farkas's theorem for the new inequalities, we see that (3.3) is satisfied with the same nonnegative multipliers $\lambda_{1}, \ldots, \lambda_{M}$.

Let us assume first that the system (3.1) contains as many linearly independent relations as the number of variables. Consider the linear programming problem:

$$
\begin{aligned}
& \operatorname{minimize} 0 \cdot \lambda_{1}+\cdots+0 \cdot \lambda_{M} \\
& \text { subject to } \lambda_{1} g_{1}+\cdots+\lambda_{M} g_{M}=g, \quad \lambda_{1} \geq 0, \ldots, \lambda_{m} \geq 0 .
\end{aligned}
$$

Starting from any basis and applying the lexicographic dual method, at the end we reach a system of the form (3.4) where either $I_{0} \geq 0, K_{0} \geq 0, \ldots$, or there exists a row in which the first term on the right-hand side is negative and all variables there have positive or zero coefficients. The second case cannot occur. In fact the lexicographic dual method guarantees that the column vectors of (3.4) are obtained from the vectors $g_{1}, \ldots, g_{M}, g$ by a nonsingular linear transformation; thus the system of linear inequalities (in the variables $\left.y_{1}, \ldots, y_{n}\right)$ :

$$
\begin{array}{ccccc}
y_{1} & & & \geq 0 & -I_{1} y_{1}-K_{1} y_{2}-\cdots \geq 0 \\
& & & \geq 0 & -I_{2} y 1-K_{2} y_{2}-\cdots \geq 0 \\
& & \ddots & & \\
& & & \\
& & & & \\
& & & & \\
& & &
\end{array}
$$

has the consequence

$$
I_{0} y_{1}+K_{0} y_{2}+\cdots \geq 0 .
$$

Now if e.g., we had $I_{0}<0, I_{1} \leq 0, I_{2} \leq 0, \ldots$, then the vector of components $y_{1}=1$, $y_{2}=\cdots=y_{n}=0$ would satisfy (3.6) and would not satisfy (3.7).

If in (3.1) we have $h(<M)$ linearly independent relations and for the sake of simplicity $g_{1}, \ldots, g_{h}$ are linearly independent, then we choose $n$-component vectors $d_{1}, \ldots, d_{n-h}$ so 
that $B=\left(g_{1}, \ldots, g_{h}, d_{1}, \ldots, d_{n-h}\right)$ is a nonsingular matrix and apply the transformation $y=B x$ for the inequalities in (3.1) and (3.2). Then (3.1) will depend only on $y_{1}, \ldots, y_{h}$ and, since the inequality in (3.2) is a consequence of the former ones, $y_{h+1}, \ldots, y_{n}$ will have zero coefficients there also. Now we can forget about $y_{h+1}, \ldots, y_{n}$ and apply the above reasoning to the system of variables $y_{1}, \ldots, y_{h}$. At the end we can reestablish $y_{h+1}, \ldots, y_{n}$ everywhere with zero coefficients and reach the original inequalities by setting $y=B x$.

Thus we have proved Farkas's theorem. We have also proved

THEOREM 3.2. If (3.2) is not a consequence of the system (3.1), then there is a linear transformation $y=B x$ with nonsingular square matrix $B$ such that for at least one $i$, the variable $y_{i}$ has negative coefficients in the new inequality (3.2) and has nonnegative coefficients in the new system (3.1).

\section{Necessary Condition for Equilibrium}

We consider a mechanical system the state of which is described by the vector $x \in R^{n}$, which is subject to the following constraints:

$$
g_{i}(x) \geq 0, \quad i=1, \ldots, m,
$$

where the functions $g_{i}: R^{n} \rightarrow R, i=1, \ldots, m$ are differentiable.

Denote by $X_{1}, \ldots, X_{n}$ the components of the forces acting on the system and suppose that equilibrium is reached at $x^{*}$. Then by Fourier's principle the inequality

$$
X_{1} \delta x_{1}+\cdots+X_{n} \delta x_{n} \leq 0
$$

is satisfied, where $\delta x_{1}, \ldots, \delta x_{n}$ are variations of the coordinates $x_{1}, \ldots, x_{n}$, i.e., small quantities with the property that the vector of components

$$
x_{1}^{*}+\delta x_{1}, \ldots, x_{n}^{*}+\delta x_{n}
$$

satisfies (4.1). In what follows we shall use general terms, but our statements can be made exact under not very restrictive mathematical conditions.

The inactive constraints in (4.1), i.e., those for which we have strict inequality at the point $x^{*}$, do not restrict small changes in the coordinates. Thus to obtain the conditions on small changes we only have to consider the constraints active at $x^{*}$. Let us assume that these are the first $M$ constraints. Then, writing $d x_{1}$ instead of $\delta x_{1}$, the Fourier principle requires that

$$
X_{1} d x_{1}+\cdots+X_{n} d x_{n} \leq 0
$$


and the increments are subject to the inequalities:

$$
\frac{\partial g_{i}\left(x^{*}\right)}{\partial x_{1}} d x_{1}+\cdots+\frac{\partial g_{i}\left(x^{*}\right)}{\partial x_{n}} d x_{n} \geq 0, \quad i=1, \ldots, M .
$$

Now we can forget about the order of magnitude of the quantities $d x_{1}, \ldots, d x_{n}$ satisfying the above inequalities. In fact if $d x_{1}, \ldots, d x_{n}$ satisfy a homogeneous linear inequality, then the same holds for $t d x_{1}, \ldots, t d x_{n}$ where $t$ is any nonnegative constant.

Let $X$ denote the vector with components $X_{1}, \ldots, X_{n}$. We shall write it in row form and also use the convention that gradients are row vectors.

If $x^{*}$ is an equilibrium point, then, using Fourier's principle, we find that the linear inequality (4.4) is a consequence of the system of linear inequalities (4.5); hence, by Farkas's theorem, there exist nonnegative numbers $\lambda_{1}, \ldots, \lambda_{M}$ such that

$$
X+\lambda_{1} \nabla g_{1}\left(x^{*}\right)+\cdots+\lambda_{M} \nabla g_{M}\left(x^{*}\right)=0 .
$$

If the system of forces is conservative, i.e., there exists a potential $V(x)$ so that at every point of the state space we have

$$
X_{i}=-\frac{\partial V}{\partial x_{i}}, \quad i=1, \ldots, n,
$$

then (4.4) becomes

$$
\frac{\partial V}{\partial x_{1}} d x_{1}+\cdots+\frac{\partial V}{\partial x_{n}} d x_{n} \geq 0
$$

Here on the left-hand side we have a total differential. Having a potential, we can start from (4.8), by applying Courtivron's principle, which states that if a mechanical system is in stable equilibrium then the potential has a local minimum, and observing that (except for pathological cases) the total differential is nonnegative at the minimum point of the function.

We can ask: Who - if anybody - deduced equation (4.6) from the inequality principle for mechanical equilibrium? To answer this question we can start by analyzing the papers cited by Farkas in [23], and we should also look at the volumes of Enzyklopädie der Mathematischen Wissenschaften published at the beginning of this century. In the four volumes on mechanics there are two papers (Voss [75] and Stäckel [71]) that mention theories of statics and dynamics under inequality constraints. These authors and Farkas cite about thirty books and papers; some of them are unfortunately not available to the other author, but Farkas, Voss, and Stäckel together very likely give a good picture of the history of the subject. Voss writes [75, p. 74]:

This case, not considered by Lagrange, was first considered, independently of Fourier, by Gauss and by Ostrogradsky ... therefore in Russia the Fourier principle is also called Ostrogradsky's principle. In France the Fourier principle has been 
less often neglected; A. A. Cournot developed Ostrogradsky's equations as early as 1827.

One paper by Ostrogradsky [67] is also cited by Farkas; Stäckel mentions [68] also.

Voss does not refer to Farkas; but Stäckel cites the papers [14], [16]. We can forgive Stäckel for not recognizing the importance of Farkas's work, because the subject of his paper is "Elementare Dynamik."

Dynamical problems subject to inequality constraints were considered by Gibbs in 1879 [39]. Nonnegativity of the multipliers in some special cases are proved by Mayer [58], [59] and Zermelo [76]. Farkas gave a more general form of the theory in 1906 [24].

Fourier, Cournot, Ostrogradsky, and Farkas seem to be the principal contributors to the present form of the necessary condition of static equilibrium. Cournot and later Ostrogradsky presented the equations (4.6) in the form of a conjecture, as we may say now. Farkas proved (4.6) by relying on Fourier's work concerning the first part of the theorem, considering a conservative system of forces, where - as it is obvious today but did not seem necessary for those in the last century dealing with mechanical problems - a constraint qualification is needed. We have to add to these that the work of Cournot was based to a great extent on the work of Poinsot [69].

Fourier and Farkas both contributed further important ideas to optimization theory. Let us summarize briefly their principal results in this respect.

- Fourier

- anticipated the formulation of the linear programming problem in 1824 [36, II., p. 325-328], [40];

- formulated the inequality principle for the mechanical equilibrium in 1798 [34];

- initiated the parametric solution of homogeneous linear inequalities in 1826 [35].

- Farkas

- proved the basic theorem concerning homogeneous linear inequalities, first mentioned in 1894 [13] and first complete proof in 1898 [17];

- gave a rigorous proof for the "dual form" of Fourier's mechanical inequality principle, first in 1894-1895 [13], [14];

- gave an elegant parametric representation for the solutions of homogeneous linear inequalities, first in 1898 [19]. 


\section{The Work of Cournot on the Problem of Equilibrium}

Antoine-Augustin Cournot (1801-1877), a famous polyhistor, was one of the greatest mathematical economists. The work of his that we analyze here was done as a contribution to mechanics. It is interesting to remark that, though optimization theory is an important tool of mathematical economics, in his famous book Recherches sur les Principes Mathématiques de la Théorie des Richesses, no application can be found of his previous investigation of the problem of mechanical equilibrium. Since the first publication of this book in 1838 several editions have appeared, e.g., [7] with the critiques of Walras, Bertrand, and Pareto, and introduction and biographical notes by Lutfalla, and [8] with the notes of Irving Fisher.

Cournot became docteur ès sciences in 1829 in Paris. His thesis [5], [6] contributed to dynamics, where he applied his earlier result published in 1827 [4]. One year earlier he published an elementary paper [3] on inequalities; there is no anticipation in that paper of any form of Farkas's theorem.

In the paper [4] that is at present most important for us, Cournot does not refer to the work of Fourier. He seems to have been unaware of the enunciation of the inequality principle by Fourier in 1798. Cournot rediscovered the principle but also derived the necessary conditions for equilibrium. We quote from his short paper [4, p. 166]

... It often happens that the constraints of the system cannot be expressed by equations; from these constraints there result conditions of equilibrium that have always been considered as not being derivable from the principle of virtual velocity and being outside of this principle (Mécanique de M. Poisson, tom. I, p. 241). Our purpose here is to show that when the constraints of the system can be expressed algebraically by inequality signs, the principle of virtual velocity, suitably modified, still applies and provides the conditions of equilibrium by a uniform method.

Let us assume that a system is subject to a certain number of similar constraints expressed by the inequalities

$$
I>0, \quad I^{\prime}>0, \quad \text { etc. } \quad J<0, \quad J^{\prime}<0, \quad \text { etc. }
$$

the signs $>$ and $<$ always being supposed not to exclude the case of the equality.

One cannot, in general, differentiate an inequality like an equation, or derive a relation between the increments of the variables; but when equilibrium conditions are sought, only two cases can appear. Either the nature of the system is such that one could suppress the constraints without changing its state, as happens if cords that connect some of its points are not taut or if the points to which certain surfaces form impenetrable obstacles do not touch these surfaces: in this case equilibrium must occur independently of the constraints and it is unnecessary to take them into account; or the system is so situated that the constraints produce their effect and can decrease the number of conditions necessary for equilibrium: then one has the present coordinate values $I=0, J=0$, etc., and if one varies these values, their increments will not 
be entirely arbitrary; on the basis of the primitive conditions, they must satisfy the relations:

(a)

$$
\delta I>0, \quad \delta I^{\prime}>0, \quad \text { etc. } \quad \delta J<0, \quad \delta J^{\prime}<0, \quad \text { etc. }
$$

In addition, when the system is subject to constraints of the kind that we are considering here, it is clear that one could suppress them, provided that forces were applied to produce the same effect; thus the resistance of a surface can be replaced by the application of a suitably oriented force normal to the surface; the constraint of a taut cord, by the application of a force oriented in the direction of the tension in the cord; etc. Let $F^{\prime}, F^{\prime}, \ldots$, be the forces applied directly to the system in the directions $f, f^{\prime}, \ldots$; and $P, P^{\prime}$ the auxiliary forces that take the place of obstacles and are directed along lines $p, p^{\prime}, \cdots$; on the basis of the principle of virtual velocity we will have the fundamental equation

$$
F \delta f+F^{\prime} \delta f^{\prime}+\text { etc. }+P \delta p+P^{\prime} \delta p^{\prime}+\text { etc. }=0 .
$$

Now it is easy to see that all virtual movements in which $P$ and $\delta p, P^{\prime}$ and $\delta p^{\prime}$, etc., would have opposite signs, would tend to overcome the obstacles that the surfaces, cord, etc., oppose to the different points of the system, and are consequently incompatible with the constraints of the system, expressed by the inequalities (a). The only movements compatible with the constraints are those for which $P$ and $p, \delta P^{\prime}$ and $\delta p^{\prime}$ have the same sign and for which, as a consequence of this, the quantities $P \delta p, P^{\prime} \delta p^{\prime}$, etc., are essentially positive.

Thus, disregarding the auxiliary forces $P, P^{\prime}$, etc., and the terms containing them in the equation of the virtual velocities, for the constraints that have to be satisfied by the system we have

$$
F \delta f+F^{\prime} \delta f^{\prime}+\text { etc. }<0 .
$$

The above "proof" given by Cournot concerns the validity of the Fourier principle. In the paper [4] Cournot then derives the nonnegativity of the Lagrangian multipliers for special cases similar to some of those investigated by Lagrange in the first part of Mécanique Analytique in case of equality constraints. When dealing with the case of a system of points lying on planes parallel to the $x y$-plane, Cournot refers to the work of Poinsot [69], first published in 1803. In fact for this special case Poinsot already obtained the conditions of equilibrium.

The papers [3], [4] of Cournot seem to be less well known than his other works. They are not listed in the bibliography of his works published in [7].

\section{The Work of Ostrogradsky on the Problem of Equilibrium}

Mikhail Vasilevich Ostrogradsky (1801-1862) contributed important results to mechanics (among other subjects). He was a student in Paris and attended the courses of Fourier, 
Poisson, Cauchy, and other well-known French mathematicians. He returned to Russia (St. Petersburg) in 1828. In 1830 he became an extraordinary member, and in 1832 an ordinary member, of the Academy of St. Petersburg.

We should mention two papers of Ostrogradsky concerning the problem of mechanical equilibrium. Farkas refers only to [67], presented in 1834 before the Academy, but the other [68] is an improved version of his theory. In the earlier paper four applications are mentioned: (a) a point that is allowed to move in one part of the space subdivided by a surface; (b) the pivoted polygon; (c) the flexible cord; (d) the incompressible liquid. Further problems are mentioned concerning dynamics.

In [68] Ostrogradsky refers to (what we now call) Farkas's theorem as an obvious algebraic fact and derives the equation of equilibrium (4.6). We reproduce here part of pages 589 and 590 of [68]:

Assume that the quantities $\delta s, \delta s^{\prime}, \delta s^{\prime \prime}, \delta s^{\prime \prime \prime}, \ldots$, belong not only to those displacements of the system, of which the reaction forces are capable, but also to all other displacements, whether possible or not; or rather consider $\delta s, \delta s^{\prime}, \delta s^{\prime \prime}, \delta s^{\prime \prime \prime}, \ldots$, to be entirely arbitrary. We have to express that the reaction forces $R, R^{\prime}, R^{\prime \prime}, R^{\prime \prime \prime}, \ldots$, are not capable of producing any displacement for the system that satisfies the conditions

$$
\delta L>0, \quad \delta L_{1}>0, \quad \delta L_{2}>0, \quad \delta L_{3}>0, \ldots
$$

the sign $>$ does not exclude equality.

Now we know that a system of forces is capable of every displacement that contributes a positive value to the total moment and of none of those that corresponds to negative or zero values of the total moment. Thus, for the reaction forces to be incapable of producing any displacements satisfying the conditions (15), it is necessary that their moment is negative or zero for these displacements; in other words it is necessary that the function

$$
R \delta s \cos \psi+R^{\prime} \delta s^{\prime} \cos \psi^{\prime}+R^{\prime \prime} \delta s^{\prime \prime} \cos \psi^{\prime \prime}+R^{\prime \prime \prime} \delta s^{\prime \prime \prime} \cos \psi^{\prime \prime \prime}+\cdots
$$

in which $\psi, \psi^{\prime}, \psi^{\prime \prime}, \psi^{\prime \prime \prime}, \ldots$, designate the angles $R \delta s, \widehat{R^{\prime} \delta s^{\prime}}, \widehat{R^{\prime \prime} \delta s^{\prime \prime}}, \widehat{R^{\prime \prime \prime} \delta s^{\prime \prime \prime}}, \ldots$, respectively, and which consequently represents the moment of the forces $R, R^{\prime}, R^{\prime \prime}, R^{\prime \prime \prime}$, $\ldots$, is negative or zero whenever $\delta s, \delta s^{\prime}, \delta s^{\prime \prime}, \delta s^{\prime \prime \prime}, \ldots$, satisfy (15).

The solution of the question of making the function

$$
R \delta \cos \psi+R^{\prime} \delta s^{\prime} \cos \psi^{\prime}+R^{\prime \prime} \delta s^{\prime \prime} \cos \psi^{\prime \prime}+R^{\prime \prime \prime} \delta s^{\prime \prime \prime} \cos \psi^{\prime \prime \prime}+\cdots
$$

negative or zero whenever the functions of the same kind, $\delta L, \delta L_{1}, \delta L_{2}, \delta L_{3}, \ldots$, are positive or zero, belongs to the most elementary algebra. It is necessary and sufficient that $R \delta s \cos \psi+R^{\prime} \delta s^{\prime} \cos \psi^{\prime}+R^{\prime \prime} \delta s^{\prime \prime} \cos \psi^{\prime \prime}+R^{\prime \prime \prime} \delta s^{\prime \prime \prime} \cos \psi^{\prime \prime \prime}+\cdots$ can be reduced to a linear function of $\delta L, \delta L_{1}, \delta L_{2}, \delta L_{3}, \ldots$, with negative coefficients. Thus we only have to make, for arbitrary $\delta s, \delta s^{\prime}, \delta s^{\prime \prime}, \delta s^{\prime \prime \prime}, \ldots$,

$$
\begin{gathered}
R \delta s \cos \psi+R^{\prime} \delta s^{\prime} \cos \psi^{\prime}+R^{\prime \prime} \delta s^{\prime \prime} \cos \psi^{\prime \prime}+R^{\prime \prime \prime} \delta s^{\prime \prime \prime} \cos \psi^{\prime \prime \prime}+\cdots \\
=\lambda \delta L+\lambda_{1} \delta L_{1}+\lambda_{2} \delta L_{2}+\lambda_{3} \delta L_{3}+\cdots
\end{gathered}
$$


and add the condition that all $\lambda$ 's be negative. Or, if one wants to avoid considering negative $\lambda$ 's, one can make

$$
\begin{aligned}
R \delta s \cos \psi & +R^{\prime} \delta s^{\prime} \cos \psi^{\prime}+R^{\prime \prime} \delta s^{\prime \prime} \cos \psi^{\prime \prime}+R^{\prime \prime \prime} \delta s^{\prime \prime \prime} \cos \psi^{\prime \prime \prime}+\cdots \\
& =-\left(\lambda \delta L+\lambda_{1} \delta L_{1}+\lambda_{2} \delta L_{2}+\lambda_{3} \delta L_{3}+\ldots\right)
\end{aligned}
$$

then all $\lambda$ 's will be positive. By the last equation and the preceding one it is evident that the moment $R \delta s \cos \psi+R^{\prime} \delta s^{\prime} \cos \psi^{\prime}+R^{\prime \prime} \delta s^{\prime \prime} \cos \psi^{\prime \prime}+R^{\prime \prime \prime} \delta s^{\prime \prime \prime} \cos \psi^{\prime \prime \prime}+\ldots$ will be negative or zero whenever the functions $\delta L, \delta L_{1}, \delta L_{2}, \delta L_{3}, \ldots$, will be positive or zero.

If we transpose all terms to the same side, the equation of equilibrium of the reaction forces becomes

$$
\begin{gathered}
R \delta s \cos \psi+R^{\prime} \delta s^{\prime} \cos \psi^{\prime}+R^{\prime \prime} \delta s^{\prime \prime} \cos \psi^{\prime \prime}+R^{\prime \prime \prime} \delta s^{\prime \prime \prime} \cos \psi^{\prime \prime \prime} \\
+\cdots+\lambda \delta L+\lambda_{1} \delta L_{1}+\lambda_{2} \delta L_{2}+\lambda_{3} \delta L_{3}+\cdots=0 .
\end{gathered}
$$

It has to hold for all $\delta s, \delta s^{\prime}, \delta s^{\prime \prime}, \delta s^{\prime \prime \prime}, \ldots$, of arbitrary magnitude and direction. But one should not forget to add to the equation (16) the inequalities

$$
\lambda>0, \quad \lambda_{1}>0, \quad \lambda_{2}>0, \quad \lambda_{3}>0, \quad \ldots
$$

Ostrogradsky made two errors. One consists of asserting Farkas's theorem without proof. Ostrogradsky's authority was so strong that many authors took the theorem for granted [58], [59], [64], [75]. The second error was discovered by Study, as communicated by Mayer [58, p. 225]. On page 583 of [68] Ostrogradsky infers that some of his inequalities should reduce to equations of equilibrium. This would have made it possible to determine the multipliers in the equation at equilibrium. He thought that those multipliers should be equal to zero which would turn out to be negative if we did not have the inequality constraints.

\section{The Work of Farkas on the Problem of Equilibrium}

Since the two papers [13], [14] are essentially the same, we quote from the German version [14]. In the introductory part of the paper we read the following:

The purpose of this paper is to show that, with a suitable modification, the method of multipliers of Lagrange can be carried over to the Fourier principle also.

In the first section of the paper Farkas deals with his inequality theorem. His proof is incomplete, however, as we pointed out. In the second section the necessary condition of equilibrium is derived: 
... the constraint expressions go over to the following

$$
\begin{array}{lll}
\sum F \delta q=0, & \sum G \delta q=0, & \ldots, \\
\sum S \delta q \geq 0, & \sum T \delta q \geq 0, & \ldots,
\end{array}
$$

and the fundamental inequality is

$$
\sum Q \delta q \leq 0 \quad \text { or } \quad-\sum Q \delta q \geq 0 .
$$

The constraint equations have to be expressed in the form of inequalities so that the system of constraint conditions appears as follows:

$$
\begin{aligned}
& \sum F \delta q \geq 0, \quad \sum G \delta q \geq 0, \quad \ldots, \\
& -\sum F \delta q \geq 0, \quad-\sum G \delta q \geq 0, \quad \ldots \\
& \sum S \delta q \geq 0, \quad \sum T \delta q \geq 0, \quad \ldots
\end{aligned}
$$

The Fourier principle requires that the inequality (12) is satisfied by all systems of values $\delta q$ that satisfy (13). It will be shown that this happens only when there are positive multipliers such that the coefficients $Q$ can be represented as homogeneous linear functions of the coefficients $F, G, \ldots,-F,-G, \ldots, S, T, \ldots$ Let $\phi^{\prime}, \psi^{\prime}, \ldots, \phi^{\prime \prime}, \psi^{\prime \prime}, \ldots, \lambda$, $\mu, \ldots$, denote these positive multipliers. We must have

$$
-Q=\left(\phi^{\prime}-\phi^{\prime \prime}\right) F+\left(\psi^{\prime}-\psi^{\prime \prime}\right) G+\cdots+\lambda S+\mu T+\cdots .
$$

The differences $\phi^{\prime}-\phi^{\prime \prime}, \psi^{\prime}-\psi^{\prime \prime}, \ldots$, may also take negative values, consequently the Fourier principle will be satisfied by those $Q$ values that can be determined from equations such as

$$
Q+\phi F+\psi G+\cdots+\lambda S+\mu T+\cdots=0,
$$

where $\phi, \psi, \ldots, \lambda, \mu, \ldots$, have the same values in the expressions for each $Q$ and moreover $\phi, \psi^{\prime}, \ldots$, are completely arbitrary, but $\lambda, \mu, \ldots$, are arbitrary nonnegative quantities. Conversely, the fundamental inequality (12) follows from the system (11) by using (14) and simple procedures.

In a further section of the paper "the two main types of application" are presented: (a) the equilibrium equation for tangential solid bodies; (b) the equilibrium equation for nonsolid bodies.

\section{On the Constraint Qualification}

The "constraint qualification" is of fundamental importance, not only from the point of view of nonlinear optimization, but also from the point of view of mechanics. Soon we shall see why. 
At the beginning of this century the axiomatic foundation of the mathematical and physical sciences was an important activity. In his famous paper [49] Hilbert urges mathematicians to axiomatize two "physical disciplines": probability theory and mechanics. The paper of Hamel [46] of 1909 is an attempt in the direction of the axiomatic foundation of classical mechanics. The Fourier inequality principle was unfortunately not included. An improved version of his axiomatics is contained in his paper [47], which appeared in 1927. There the inequality principle of Fourier is already mentioned as one of the axioms: Axiom II $2 k$ on page 17 . On page 33 concerning "Das Energieprinzip," Axiom II $5 c \beta$ declares, denoting the potential by $U$, that $\delta U \geq 0$ is a necessary condition for equilibrium. Hamel had to establish consistency between the two axioms and this could only be done by a "constraint qualification"; in fact we find it in Axiom II $5 c \gamma$, on page 33. It requires that to every mass particle there correspond a scalar function $u$ such that the following equality holds:

$$
\delta U=\sum d m \nabla u \delta r
$$

where $d m$ denotes the mass and $r$ the state of a particle. If instead of (8.1) we require

$$
\delta U=\nabla U \delta r
$$

where $r$ denotes the state of the whole system of particles, then we obtain essentially the Karush-Kuhn-Tucker constraint qualification. Equation (8.2) implies (8.1) because we can generate the $u$ functions for the purpose of satisfying (8.1) in such a way that in $U$ we subsequently fix all variables except for those belonging to one particle.

Unfortunately Hamel was unaware of the existence of Farkas's theorem. Even in his Theoretische Mechanik, first published in 1949, this theorem is not referred to, though part of the pages $69-70,517-518$, are devoted to the Fourier inequality principle. There we also see that his "constraint qualification" is not derived rigorously and his reasoning concerning the Fourier principle is more heuristic.

\section{Miscellaneous Remarks Concerning Linear Inequalities}

Farkas's most important results concerning the Fourier principle and the theory of linear inequalities are summarized in his papers [13], [14], [23].

The parametric representation of the solutions of linear inequalities was initiated by Fourier [35]. Minkowski gave the representation of all solutions using extremal rays [60]. In the parametric representation given by Farkas [19], [23], it is particularly simple to generate the rays whose convex combinations constitute all solutions of the linear inequalities. Writing $z_{1}, \ldots, z_{n}$ instead of $d x_{1}, \ldots, d x_{n}$ in (4.5) and (4.6), we can represent all solutions of (4.5) in a parametric form, insert it into (4.4), and, if the number of variables and the active constraints in (4.5) is not large, we can solve the equilibrium problem in some 
cases. For this we have to know which are the active constraints in (4.5). This method was recommended by Farkas [19]. The application of the Farkas parametric representation technique for linear programming is perhaps best done as in the paper by UzAWA [74]. He completes one inequality to equality (if necessary), eliminates the nonzero constants on the right-hand side from the other constraints, inserts the parametric form of the solutions of these into the remaining equality and the objective function, and finds the optimal solution.

The papers [21], [22] in Hungarian and German, respectively, have the same content. Farkas gave a further mechanical application of his theorem on linear inequalities. This concerns the decomposition of the forces of reaction in a mechanical system into shocks and others satisfying the negatives of the constraints given for the displacements (Voss mentions in [75, p. 25] that this kind of distinction between the forces is attributed to Painlevé). The mathematical results of the paper are reproduced in [23]. The book [20], in Hungarian, does not contain new results as compared to his earlier papers and to the paper [23].

Between 1902 and 1917 Farkas did not publish on linear inequalities. In 1917, after Haar generalized Farkas's theorem for the inhomogoneous case, Farkas returned to the area and published further papers [28], [29], [31] on system of linear inequalities. The papers [25], [26], [27], [30] are also partially relevant; [30] is the German version of [25].

Haar wrote three papers on linear inequalities [42], [43], [44]. The first two are essentially Hungarian and German versions of the same paper. He gave the following generalization for Farkas's theorem (we shall use the notation of Section 3).

Theorem 9.1. If the linear inequality

$$
g^{\prime} x \geq b
$$

is a consequence of the linear inequalities

$$
g_{i}^{\prime} x \geq b_{i}, \quad i=1, \ldots, M,
$$

i.e., if every $x$ satisfying (9.2) also satisfies (9.1), then there exist nonnegative constants $\lambda, \lambda_{1}, \ldots, \lambda_{M}$ such that for every $x \in R^{n}$ we have

$$
g^{\prime} x-b=\sum_{i=1}^{M} \lambda_{i}\left(g_{i}^{\prime} x-b_{i}\right)+\lambda .
$$

This is the same statement referred to by Kuhn and Tucker in a footnote supplied to von Neumann's manuscript [61]. This concerns the duality theorem of linear programming proved by Gale, Kuhn, and Tucker [37].

Haar remarked [42], [44], that the theory of linear inequalities was developed by Farkas and Minkowski. The famous book of Minkowski [60] also contains results on linear inequalities (pages 39-45 in both editions). He considered a finite system of homogeneous 
linear inequalities from two points of view: to represent them in a parametric form and to discover those which are superfluous, i.e., can be omitted without changing the set of solutions. This latter problem led him to prove a theorem closely related to Farkas's theorem mentioned in Section 3. For the sake of completeness, we present here the exact statement of Minkowski's theorem.

We assume that in the system (3.1) the number of linearly independent relations equals $n$, the number of components of $x$. This causes no loss of generality, as Minkowski remarked. We also assume that there exists at least one $x$ for which (3.1) holds with all strict inequalities. Such an $x$ is called essential. An essential $x$ is said to be an extremal ray of the cone (3.1) if $x$ is not the sum of two nonzero vectors which satisfy (3.1) and neither of them is a constant multiple of the other.

Theorem 9.2. Among the linear forms $g_{i}^{\prime} x \geq 0, i=1, \ldots, M$ those which are 0 for $m-1$ linearly independent extremal solutions have the property that each of them is essential and all other forms can be expressed as linear combinations of them with nonnegative weights.

For further references to early papers on linear inequalities see [9].

\section{References}

Remarks. In the list given below the name of Farkas appears with the initials J. or Gy. Up to the beginning of this century it was customary to translate the given name into the language of the paper. "J." refers to the German name Julius; "Gy." refers to the Hungarian name Gyula, and these two names were supposed to be the same.

Volumes of papers presented at an academy frequently have double year-assignments. One indicates the year(s) when the papers in the volume were presented before the academy, whereas the other indicates the year when the publisher published the volume. In the reference list below the latter date is always given.

[1] K. J. Arrow, L. Hurwicz, and H. Uzawa, eds., Studies in Linear and Nonlinear Programming, Stanford University Press, Stanford, Calif., 1958.

[2] E. M. L. BEALE, Cycling in the dual simplex algorithm, Naval Research Logistics Quarterly, 2 (1955) 269-276.

[3] A. Cournot, Sur le calcul des conditions d'inégalité, annoncé par M. Fourier, Bull. Sci. Math. (Première Section du Bulletin Universel des Sciences et de l'Industrie, publié sous la dir. de Férussac), 6 (1826), 1-8. 
[4] A. Cournot, Extension du principe des vitesses virtuelles au cas où les conditions de liaison du système sont exprimées par des inégalités, Bull. Sci. Math. (Première Section du Bulletin Universel des Sciences et de l'Industrie, publié sous la dir. de Férussac), 8 (1827) 165-170.

[5] A. Counnot, Mémoire sur le mouvement d'un corps rigide, soutenu par un plan fixe, J. Reine Angew. Math., 5 (1830) 133-162, 223-249.

[6] A. Cournot, Du mouvement d'un corps sur un plan fixe, quand on a égard à la résistance du frottement, J. Reine Angew. Math., 8 (1832) 1-12.

[7] A. Cournot, Recherches sur les Principes Mathématiques de la Théorie des Richesses, Nouvelle Édition, Marcel Rivière, Paris, 1938.

[8] A. Cournot, Researches into the Mathematical Principles of the Theory of Wealth, R. D. Irwin, Homewood, Ill., 1963.

[9] L. L. Dines and N. H. McCoy, On linear inequalities, Proc. and Trans. of the Royal Soc. of Canada, 3rd Series, Section 3, Mathematical, Physical and Chemical Sciences, 27 (1933) $37-70$.

[10] L. Dirichlet, Sur un moyen général de vérifier l'expression du potential relatif à une masse quelconque, homogène ou hétérogène, J. Reine Angew. Math., 32 (1846) 80-84.

[11] L. Dirichlet, Über die Stabilität des Gleichgewichts, J. Reine Angew. Math. 32 (1846) $85-88$.

[12] Encyklopädie der Mathematischen Wissenschaften, Teubner, Leipzig, 1901-1908, Vierter Band, Mechanik, Erster Teilband.

[13] Gy. Farkas, A Fourier-féle mechanikai elv alkalmazásai (Applications of the mechanical principle of Fourier), Matematikai és Természettudományi Értesítő, 12 (1894) 457-472.

[14] J. Farkas, Über die Anwendungen des mechanischen Princips von Fourier, Mathematische und Naturwissenschaftliche Berichte aus Ungarn, 12 (1895) 263-281.

[15] Gy. Farkas, A Fourier-féle mechanikai elv alkalmazásainak algebrai alapjáról (The algebraic basis of the applications of the mechanical principle of Fourier), Mathematikai és Physikai Lapok, 5 (1896) 49-54.

[16] J. Farkas, Die algebraischen Grundlagen der Anwendungen des Fourierschen Princips in der Mechanik, Mathematische und Naturwissenschaftliche Berichte aus Ungarn, 15 (1899) 25-40.

[17] Gy. FARKas, A Fourier-féle mechanikai elv alkalmazásának algebrai alapja (The algebraic basis of the application of the mechanical principle of Fourier), Mathematikai és Természettudományi Értesítő, 16 (1898) 361-364.

[18] J. Farkas, Die algebraische Grundlage der Anwendungen des mechanischen Princips von Fourier, Mathematische und Naturwissenschaftliche Berichte aus Ungarn, 16 (1899) 154-157.

[19] Gy. Farkas, Paraméteres módszer Fourier mechanikai elvéhez (Method of parameters in the mechanical principle of Fourier), Mathematikai és Physikai Lapok, 7 (1898) 63-71.

[20] Gy. Farkas, Vectortan és az egyszerü inaequatiok tana (Theory of vectors and simple inequalities), Kolozsvár, 1900.

[21] Gy. Farkas, Általános mechanikai elvek az aether számára (General mechanical principles of the ether), Mathematikai és Természettudományi Értesítő, 19 (1901) 99-122.

[22] J. Farkas, Allgemeine Principien für die Mechanik des Aethers, Archives Néerlandaises, Série 2, 4 (1900) 56-75 (Livre jubilaire dédié à H. A. Lorentz).

[23] J. Farkas, Theorie der einfachen Ungleichungen, J. Reine Angew. Math., 124 (1901) 1-27. 
[24] J. Farkas, Beiträge zu den Grundlagen der analytischen Mechanik, J. Reine Angew. Math., 131 (1906) 165-201.

[25] Gy. Farkas, Biztos egyensúly potenciál nélkül (Stable equilibrium without potential), Mathematikai és Természettudományi Értesítő, 32 (1915) 339-354.

[26] Gy. Farkas, Nemvonalas egyenlőtlenségek vonalassá tétele (Conversion of nonlinear inequalities into linear ones), Mathematikai és Természettudományi Értesítő, 35 (1917) 41-50.

[27] Gy. Farkas, Multiplicatoros módszer négyzetes alakokhoz (Method of multipliers for quadratic forms), Mathematikai és Természettudományi Értesítő, 35 (1917) 51-53.

[28] Gy. Farkas, Egyenlőtlenségek alkalmazásának új módjai (New ways to apply inequalities), Mathematikai és Természettudományi Értesítő, 36 (1918) 297-308.

[29] Gy. Farkas, A lineáris egyenlőtlenségek következményei (Consequences of linear inequalities), Mathematikai és Természettudományi Értesítő, 36 (1918) 397-408.

[30] J. Farkas, Stabiles Gleichgewicht ohne Potential, Mathematische und Naturwissenschaftliche Berichte aus Ungarn, 32 (1923) 43-50.

[31] Gy. Farkas, Alapvetés az egyszerü egyenlőtlenségek vektorelméletéhez (Foundation of the vectoriel theory of simple inequalities), Mathematikai és Természettudományi Értesíto, 43 (1926) $1-3$.

[32] I. FÉnYEs, Megjegyzések és kiegészítések a mechanika elveinek Farkas Gyula-féle tárgyalásmódjához (Remarks on and extensions of the treatment of mechanical principles by Farkas), Fizikai Szemle, 4 (1954) 99-102.

[33] L. Filep, Farkas Gyula (1847-1930), Természet Világa 1976/9, 410-411.

[34] J. Fourier, Mémoire sur la statique, Journal de l'École Polytechnique, 5 (1798), in [36] vol. 2, $478-520$.

[35] J. Fourier, Solution d'une question particulière du calcul des inégalités, Nouveau Bulletin des Sciences par la Société Philomatique de Paris, 1826, in [36] vol. 2, 317-319.

[36] J. Fourier, Oeuvres, Gauthier-Villars, Paris, 1888.

[37] D. Gale, H. W. Kuhn, and A. W. Tucker, Linear programming and the theory of games, in [52] 317-329.

[38] C. F. Gauss, Über ein neues allgemeines Grundgesetz der Mechanik, J. Reine Angew. Math., 4 (1829) 232-235.

[39] J. W. Gibis, On the fundamental formulae of dynamics, Amer J. Math., 2 (1879) 49-64.

[40] I. Grattan-Guinness, Joseph Fourier's anticipation of linear programming, Operational Research Quarterly, 21 (1976) 361-364.

[41] A. T. Grigorian, Ocherki Istorii Mechaniki v Rossii (Outline of the History of Mechanics in Russia), Akad. Nauk SSSR, Moskva, 1961.

[42] A. HaAR, A lineáris egyenlőtlenségekről (On linear inequalities), Mathematikai és Természettudományi Értesítő, 36 (1918) 279-296.

[43] A. HaAR, Die Minkowskische Geometrie und die Annäherung an stetige Funktionen, Math. Ann., 78 (1918) 294-311.

[44] A. HaAr, Über lineare Ungleichungen, Acta Sci. Math., 2 (1924) 1-14.

[45] A. HaAr, Gesammelte Arbeiten, Akadémiai Kiadó, Budapest, 1959.

[46] G. HameL, Über die Grundlagen der Mechanik, Math. Ann., 66 (1909) 350-397. 
[47] G. Hamel, Die Axiome der Mechanik, in [48], 1-42.

[48] Handbuch der Physik, H. Geiger and K. Scheel, ed., Band 5, Grundlagen der Mechanik, Mechanik der Punkte und Starren Körper, Springer, Berlin, 1927.

[49] D. Hilbert, Mathematische Probleme (Vortrag gehalten auf dem internationalen Mathematiker-Kongress zu Paris, 1900), Nachrichten von der Königl. Gesselschaft der Wissenschaften zu Göttingen. Mathematisch-physikalische Klasse (1900) 253-297.

[50] F. John, Extremum problems with inequalities as subsidiary conditions, in [72], $187-204$.

[51] W. Karush, Minima of Functions of Several Variables with Inequalities as Side Conditions, Master's Thesis, Dept. of Math., University of Chicago, 1939.

[52] T. C. Koopmans, ed., Activity Analysis of Production and Allocation, Wiley, New York, 1951.

[53] H. W. Kuhn and A. W. Tucker, Nonlinear programming, in [62], 481-492.

[54] H. W. Kuhn and A. W. Tucker, Nonlinear programming: A historical view, in [63], 1-26.

[55] J. L. Lagrange, Mécanique Analytique I-II, Paris, 1788.

[56] J. L. Lagrange, Oeuvres, Gauthier-Villars, Paris, 1888.

[57] C. E. Lemke, The dual method for solving the linear programming problem, Naval Research Logistics Quarterly, 1 (1954) 36-47.

[58] A. Mayer, Über die Aufstellung der Differentialgleichungen der Bewegung für reibungslose Punktsysteme, die Bedingungsungleichungen unterworfen sind, Berichte über die Verhandlungen der königlich sächsischen Gessellschaft der Wissenschaften zu Leipzig, MathematischPhysische Classe, 50 (1898) 224-244.

[59] A. Mayer, Zur Regulierung der Stosse in reibungslosen Punktsystemen, die dem Zwange von Bedingungsungleichungen unterliegen, Berichte über die Verhandlungen der königlich sächsischen Gesellschaft der Wissenschaften zu Leipzig, Mathematisch-Physische Classe, 50 (1898) 245-264.

[60] H. Minkowski, Geometrie der Zahlen, Teubner, Leipzig and Berlin, 1st ed., 1896; 2nd ed., 1910.

[61] J. von Neumann, Discussion of a maximum principle, Collected Works, vol. 6, 89-95.

[62] J. Neyman, ed., Proc. of the Second Berkeley Symposium on Mathematical Statistics and Probability, University of California Press, Berkeley, Calif., 1951.

[63] Nonlinear Programming, SIAM-AMS Proceedings, vol. 9, American Mathematical Society, Providence, R. I., 1976.

[64] L. Nordheim, Die Prinzipe der Dynamik, in [48], 43-90.

[65] R. Ortvay, Farkas Gyula tudományos müködése (The scientific work of Gyula Farkas), Matematikai és Fizikai Lapok, 34 (1927), 5-25.

[66] R. Ortvay, Farkas Gyula emlékezete (In memory of Gyula Farkas), Az MTA Tagjai Felett Tartott Emlékbeszédek (Obituaries of Members of the Hungarian Academy of Sciences), 21 (1933) 15.

[67] M. Ostrogradsky, Considérations générales sur les moments des forces, Mémoires de l'Académie Impériale des Sciences de Saint-Pétersbourg, Sixième Série, 1 (1838), 129-150.

[68] M Ostrogradsky, Mémoire sur les déplacements instantanés des systèmes assujettis à des conditions variables, Mémoires de l'Académie Impériale des Sciences de Saint-Pétersbourg, Sixième Série, 1 (1838) 565-600. 
[69] L. Poinsot, Éléments de Statique, Douzième Éd., Gauthier-Villars, Paris, 1877, first published in 1803.

[70] A. Prékopa, Lineáris programozás, Bolyai János Mathematikai Társulat, Budapest, 1968.

[71] P. STÄCkel, Elementare Dynamik der Punktsysteme und starren Körper, in [13], 435-691.

[72] Studies and Essays, presented to Courant on his 60th birthday, Interscience, New York, 1948.

[73] B. SzÉnÁssy, A Magyarországi Matematika Története (History of Mathematics in Hungary), Akadémiai Kiadó, Budapest, 1970.

[74] H. UzaWA, An elementary method for linear programming, in [1], 179-188.

[75] A. Voss, Die Prinzipien rationellen Mechanik, in [12], 2-121.

[76] E. Zermelo, Über die Bewegung eines Punktsystemes bei Bedingungsungleichungen, Nachrichten von der königl. Gessellschaft der Wissenschaften zu Göttingen. Mathematischphysikalische Klasse (1898) 306-310.

Computer and Automation Institute of the Hungarian Academy of Sciences, Kende 1. 13-17, Budapest, Hungary, 1111. 